\title{
DIETARY ACCULTURATION AND INTEREST IN MODIFICATION OF STAPLE FOODS: A PRELIMINARY QUALITATIVE STUDY WITH RICE
}

\author{
PHAN THUY XUAN UYEN ${ }^{1 *}$, EDGAR CHAMBERS IV ${ }^{2}$ \\ ${ }^{1}$ Institute of Biotechnology and Food Technology, Industrial University of Ho Chi Minh City \\ ${ }^{2}$ Sensory Analysis Center, Kansas State University, 1310 Research Park Dr., Manhattan, KS 66502 \\ phanthuyxuanuyen@iuh.edu.vn
}

\begin{abstract}
This preliminary study examined differences in dietary perceptions and beliefs of a staple food product and a health focused modification of that food product in a focus groups study of native Vietnamese in Vietnam (VNV) and Vietnamese immigrants to the United States (USV). The concepts investigated were rice product awareness and beliefs, use and preparation of rice, and overall interest in value-added brown rice product concepts incorporating health related language. While white rice was well accepted and daily consumed by both USV and VNV, the brown rice product concept, despite its numerous health benefits, was not readily accepted by Vietnamese consumers, either from US or Vietnam. Both sets of consumers had culturally negative associations of brown rice with poverty, aging, and illness in Vietnam and those perceptions had not changed with immigration. Neither USV nor VNV consumers considered health benefits as key factors for rice consumption, a staple food in all of their diets, a difference from Caucasian US participants studied earlier. Exposure to US culture seemed to have little impact on USVietnamese's rice eating habits. Thus, for a staple food product it appears that it would take time and considerable effort to impact the Vietnamese immigrants' cultural foodways.
\end{abstract}

Keywords: culture; rice; focus groups; dietary acculturation

\section{INTRODUCTION}

Immigration has long become a worldwide trend. There are few countries that do not have an ethnic group that originated from one or more other countries. People move to different countries for many different reasons: seeking refuge, better work opportunities, family, study, marriage and others. The United States is a good example of a "multiethnic" culture as it is called home by many people from all over the world [8]. The US immigrant population has grown dramatically in the last century, representing about $13 \%$ of the total US population (US Census Bureau, 2011), mostly Asians and Hispanics. European countries also among those with large immigrant populations, such as South Asians in the United Kingdom, Africans in France, Turks in Germany, Latin Americans in Spain, and Surinamese in the Netherlands for example [2]. With such remarkable increase in immigrant populations around the world, issues related to health, diet, lifestyle, culture and belief of these ethnic minorities have drawn attention from different research domains such as public health, dietetics, nutrition, food science and technology, psychology and sensory science. Immigration often brings changes in a person's lifestyle and environment, which can result in major changes in food habits, and often a less healthy diet. For instance, Mexican immigrants to the United States were reported to consume less whole grain and legumes but more "Western" foods (e.g. hamburgers) [8]. A majority of ethnic groups in Europe (South Asians, Chinese, Turks, Mexicans, African Caribbeans) also changed their eating habits, combining parts of their traditional diet with some of the less healthy elements of the Western diet [2]. Such changes result from various factors, including food availability, income, convenience, religion, age, country of origin, and beliefs [2]. Dietary changes of immigrants are known as "dietary acculturation", which is the process of adopting the eating patterns/food choices of the host country [7]. It often is influenced by the relationship of socioeconomic, demographic, and cultural factors with exposure to the host culture [8]. In addition, availability of products usually is quite different in the new country as compared to the former country of residence.

Studies have shown that immigrants with dietary changes often face higher chronic disease risk, for instance, Asian-American female immigrants to the US with residence of a decade or longer have an $80 \%$ higher risk of breast cancer than more recent immigrants [14]. Therefore, understanding dietary acculturation of ethnic groups should benefit nutrition practitioners, policy-makers, food scientists, and dietitians in designing products and dietary interventions and promoting healthy eating for ethnic minorities. 
This preliminary study examined differences in dietary perceptions and beliefs of a staple food product (rice) and a health focused modifications of that product (brown rice alternatives) in an Asian minority in the United States and their counterparts living in their original country. By comparing to recent (1-5 years) immigrants to a group of non-immigrants from the same country, the study was expected to provide some add-in knowledge to understanding dietary acculturation and its influence on food habits of immigrants. This study also demonstrated focus groups as a qualitative method often used towards the earlier phases in product development to uncover potential reasons for products' like/dislike [1].

\section{MATERIALS AND METHODS}

\subsection{Participants}

Focus group participants included Vietnamese with US residence of 1-5 years (USV) and Vietnamese residing in Vietnam (VNV). Two USV focus groups consisted of twelve participants (six females and six males, ages 18-44 years) who had lived in the US for at least one year but less than five years. VNV counterparts included sixteen participants (eleven females and five males, ages 20-65 year old), all Vietnamese speakers, assigned into two groups (eight per group based on their availability). All participants were compensated for their time. To qualify for this study, participants had to consume grain and rice products at least twice per month, be older than 18 years, and have no knowledge or professional training related to food science, product development, marketing, and health. Mini focus groups, consisting of four to six participants, are becoming popular because they are easier to set up and participants are more comfortable sharing their opinions [3]. Other researchers have conducted focus groups consisting of five to eight [11] or four to seven participants each [12,3]. Focus groups of four to eight participants each were employed in this study.

\subsection{Procedure}

The study used focus groups, a qualitative technique, where participants engage in group interviews guided by a moderator [13]. Two 90-minute focus groups, including USV participants, were conducted at the Sensory Analysis Center at Kansas State University, Manhattan, Kansas. These focus group discussions took place at a round table in a room facilitated with a two-way mirror for audio and video recording, observing, and note taking. The discussions were guided in English by a native US trained focus group moderator (RIVA Institute, Bethesda, MD, USA) and translation into Vietnamese was provided by a second Vietnamese native moderator, when needed. The other two focus groups with VNV, were conducted at Ho Chi Minh-city University of Technology, Vietnam (HCMUT). These focus groups took place at a round table in a quiet classroom, facilitating audio recording only. These discussions were led by the native Vietnamese moderator who was experienced in conducting focus groups and had served as the translator in the US based focus groups. The same moderators guide (after translation) was used in both locations. The guide was translated from English to Vietnamese by the Vietnamese moderator and the translated version was verified for accurateness and comprehensibility by a Vietnamese professor at HCMUT who spoke both English and Vietnamese.

To efficiently moderate the discussions, the moderators used a guide specifying general and specific questions and activities. General questions explored consumer awareness and perception of rice and rice products, usage and preparation of rice, and factors underlying purchasing/consuming rice. The focus groups carried out in-depth discussions exploring consumer interests, attitudes, and concerns toward new brown rice product ideas. Table 1 shows the synopsis of the moderators focus group discussion guide.

Table 1. Demonstration of the moderator's guide used in the focus group on healthy rice product

\section{INTRODUCTION}

1.1 Greetings and acknowledgment.

1.2 Disclosure of videotaping and observers

1.3 Guidelines

1.4 Self-introduction

\section{WARM-UP}


2.1 Describe a typical (evening meal) dinner

2.2 Driving factors for choosing what to eat for a meal.

2.3 (For US-Vietnamese groups) Changes in food consumption comparing when living in the US to when lived in Vietnam; specifically, products purchased at the supermarket.

2.4 General perception of "rice" (to what rice is associated)

\section{ACTIVITY 1 - Group activity - Awareness of rice/rice products}

Divide the participants into two groups. Each group thinks of any products that contain rice and lists it on the flip chart. The products can be rice itself or a product that contains rice. Then discuss the topics below.

3.1 (for US-Vietnamese groups) Types of rice consumed on a daily basis (in U.S.) and how they are similar / different to the rice consumed when lived in Vietnam.

3.2 Describe and discuss the values of different varieties of rice

\section{ACTIVITY 2 - Individual Activity - Actual usage of rice products}

Ask the participants to write down on a sheet of paper the products they eat on a regular basis that contain rice and when they typically eat it (time of day). Then discuss the following topics.

4.1 The reasons to purchase/eat the rice products they wrote down.

4.2 (for US-Vietnamese) How similar or different those rice products are to the rice ate when living in Vietnam

\section{PREPARATION OF RICE AT HOME}

Discuss rice (whole grain form), and how it is prepared.

5.1 How to prepare rice at home

5.2 (for US-Vietnamese groups) How often to prepare/cook rice as compared to when lived in Vietnam

5.3 Portion of rice in a meal

\section{NEW PRODUCT IDEAS DISCUSSION - ATTITUDES AND BELIEFS}

\section{Product Idea \#1}

This new brown rice comes from the process of bringing regular brown rice into germination. The new rice, therefore, is softer and contains higher amounts of vitamins B1, B6, E, dietary fiber, minerals as well as antioxidants. Moreover, a significant quantity of Gamma-Amino Butyric Acid (GABA) is also found in this rice. GABA is known for its calming effect on the nervous system, and its benefit in fighting insomnia, depression and other neurological conditions. A regular intake of GABA helps improve kidney function, lower blood pressure and reduce sleeplessness.

6.1 What caught participants attention in the product idea

6.2 Participants' thoughts about brown rice

6.3 Where the participants expect to learn this kind of information about the new product (package, commercial, friends, article)

6.4 Anything in the paragraph that the participants did not understand or that confused them

6.5 What else the participants want to know about the product

6.6 What changes the participants want to make to this product description to make it better

\section{Product Idea \#2}

This new brown rice is known for its superior nutritional value. It contains dietary fiber, various vitamins, and anti-oxidants. This rice also contains GABA, an amino acid known for its soothing effect on the nervous system, fighting depression, lowering blood pressure, and reducing sleeplessness. This rice can be cooked and digested easily thanks to its surprisingly soft texture for a brown rice. This product combines the health benefits of brown rice with a softer texture similar to white rice.

7.1 How this product idea compares to the first product idea

7.2 Anything in the paragraph that the participants did not understand or that confused them

7.3 What changes the participants want to make to this product description to make it better

7.4 Who they expect to be most interested in this product

\section{CLOSURE}

8.1 Ask the participants not to discuss the product ideas with anyone outside of this room.

8.2 Thank them for their participation 
Observers were used at both locations to help the focus group moderator summarize the focus group information. The focus groups also were audio- and video-taped in order to transcribe and review the focus group.

\subsection{Data analysis}

Upon completion of each focus group, the moderator and observers held a debriefing session to summarize key points from the discussion. Following the discussion guide, notes from the moderator and observers were reviewed one point at a time. Researchers used the summaries to form an overview of what was learned from the focus groups. All focus group audio and videotapes were transcribed with comments and discussions grouped into main "themes" identified in the debriefing sessions. Researchers used flip charts and written ballots from the sessions to explore trends in participant responses.

\section{RESULTS AND DISCUSSION}

\subsection{Perception and use of rice}

Though both USV and VNV participants reported rice as the main item in their dinner meal, their perceptions of rice were slightly different. USV participants perceived rice as "Asian", "familiar", "everyday", "filling", "smelling good", and "white" and VNV participants associated rice with "traditional food", "a food habit from ancestors", "essential", thus "irreplaceable". It appears that living in a foreign country has made the USV cohort aware of their racial/ethnic identity more than those living in their home country. Thus, "Asian" is a response from USV while VNV just considered it as traditional. The word rice reminded USV groups of typical Vietnamese rice products as these types of products are not always available, especially in Kansas where the study took placed. The same word triggered different things for the VNV. They mentioned sensory and textural properties of cooked rice, and quality corresponding to price. Availability and accessibility have come to play in immigrants' perception of their traditional food products. Besides, convenience and availability were considered the most influencing factor on USV groups' choice of food items that go with rice. Convenience and availability, however, were not mentioned by VNV participants when they considered food items to serve with rice.

However, these two populations were similar in their rice consumption. They did not consume any processed rice products. When asked to list all products made of rice, they reported only traditional rice products from their home country, and they all personally cooked (using a rice cooker) and consumed rice (mostly white rice) at home for every meal. Rice always takes up the largest portion on their plate. These results were not surprised for the USV as it was consistent with Gilbert and Khokhar's findings [2] that staple foods consumption tend to remain unchanged for a long period of time.

\subsection{Changes in food habits and rice consumption of US-Vietnamese}

Responding to the question "How have the things you eat here (in the US) compared to what you ate when you were in Vietnam?" USV participants stated that the greatest difference existed in the ratio between meat and fresh vegetables. They ate more vegetables and less meat in Vietnam but consumed the exact opposite in the US. They also consumed fewer dairy products (mostly milk) in Vietnam on a daily basis than in the US. The reason for these changes was cost. Fresh vegetables were cheaper in Vietnam but more expensive in the US; meanwhile, meat and milk were expensive in Vietnam but were considered "cheap" for Vietnamese consumers in the US. Expressing that she could not find good vegetables and ingredients to cook dishes similar to what she used to eat in Vietnam, a participant stated, "(Vietnamese) foods I cook here are less tasty than foods I used to cook in Vietnam." Participants claimed that breakfast held the most differences for them after coming to the US. In Vietnam, they usually ate noodles and other rice dishes for breakfast, but the most common breakfast items in the US for them were cereal milk, and bread. Grocery shopping habits illustrated another change for this group. In Vietnam, participants typically shopped every day, but in the US they commonly shopped only once per week. Therefore, this difference caused the amount of groceries purchased during one grocery shopping trip to change (i.e., in Vietnam small amounts for one day's use were purchased, while in the US groceries were bought for use throughout the entire week). Because fresh vegetables are perishable and difficult to keep fresh in fridge, USV participants preferred buying them less than other groceries that they can refrigerate or freeze. 
This group's rice eating habits did not change. Their meals always contained white rice as the main item. Rice cookers were often used to make rice in both places; however, participants reported the use of different rice cultivars. After living in the US, these participants switched from using Vietnamese rice to Thai, Korean, or Japanese rice. This might partly due to lack of availability of Vietnamese rice in the grocery store. Yet it was also because of quality. Participants stated that, "Rice here (US) is better. It is cleaner and has a better flavor" or "Rice here (US) is better in quality". USV participants claimed that rice consumed in the US differed in texture and flavor from rice in Vietnam. Participants preferred Thai and Korean rice to American rice because they found American rice dry. "Soft" and "sticky" described the two properties of rice that most US-Vietnamese participants liked.

\subsection{Perceptions of brown rice}

USV and VNV both perceived brown rice as different in taste and texture from white rice. Brown rice was said to be tougher than white rice. However, both USV and VNV participants claimed that the brown rice did not taste as good, and that it contains a stronger flavor than white rice. Participants from both Vietnamese groups agreed that brown rice is not soft, not sticky, not sweet and somehow "off" in flavor. VNV participants added that brown rice is expensive.

All participants from both groups expressed awareness that brown rice contains more nutritional value (e.g., vitamins and fiber) than white rice. However, the participants, either living in the US or in Vietnam, had negative perceptions about brown rice because they associated it with a period of poverty in Vietnamese history. Participants explained that most Vietnamese know that brown rice includes vitamins and health benefits, but they do not want to use this product because they are uncertain of how the product should be used. Some had negative experiences with brown rice, and some remarked "Not familiar". All Vietnamese participants agreed that brown rice was for old people. Trial of a new brown rice product for both USV and VNV was a risk, both financially and in flavor/taste.

\subsection{Attitudes toward a value-added brown rice (GABA rice)}

\subsubsection{USV participants}

The first product idea (Table 1 - Product Idea \#1) did not gain much interest from this group. The variation in responses reflected concerns over this idea. USV participants indicated strong concerns about the germination process. They wanted to know how far the rice would be germinated. One participant also associated the rice germination process with bean sprouts. They also expressed curiosity about GABA and whether GABA was natural or artificial. Their interest included concerns over taste, texture, health benefits, and functional effects, but taste of the product was the top concern because previous negative experience with the taste of brown rice. They also doubted the product's functional effect, thus the functional effects must be tested to convince them. This group expressed other concerns about the new rice product (e.g., package size, preparation methods, and availability).

All USV participants liked the second description (Table 1 - Product Idea \#2) better because it was easier to understand. They all indicated interested to very interested. The "soft texture similar to white rice" attracted USV participants to the idea, and they expressed that rice tasting similar to white rice would be acceptable.

USV participants thought this new rice product was for health conscious people, diabetes patients, professional athletes who need to take good care of their bodies, elderly, and people with digestion problems. They would like to have information about the product on the package and information boards near their residence.

\subsubsection{VNV participants}

Different from the USV groups, VNV groups indicated somewhat to high interests in both product ideas. However, they showed strong concerns about the germination process and required to know more about it before any further action could be concerned. One of their concerns was if the germination process would change the components in the rice and produce any toxic substance. One participant doubted how the rice could become that nutritious by only germinating. Similar to the USV groups, the VNV participants doubted the effectiveness of the new rice. 
The first description (Table 1 - Product Idea \#1), due to containing many scientific names of the product compositions, was found difficult to understand for these groups. The term GABA was considered difficult to understand and required more explanation. One participant associated germination with "being poisonous" because it reminded him of potato when germinated. He added that the rice would not be brown rice anymore once germinated because "germination often takes away the nutrients from the grain", said by another participant, thus "how could it be more nutritious?" The participants brought up the need of having evidences to support the nutritional and functional values of the new rice because "anything said without evidence is not convincing". Taste was the main concern of these groups, "Is it bitter?" one female participant wondered. Appearance was another concern. "If the color is not good, people won't like it" or "If the product contains the sprouts then people will think it has gone bad and would not buy it", participants concerned. Therefore, the new rice needs to be acceptable in both taste and appearance. Other information such as if the rice could be used daily was also questioned.

The second description (Table 1 - Product Idea \#2) was seen as clearer and easier to understand. The VNV participants all thought the wordings are user-friendly, for instance, "similar to white rice" or "easy to digest". However, this description was still not satisfied because it did not provide details of the germination process and the purpose of doing so as well as any evidence to support its nutritional values. Though, the word "germination" was considered important in the description as it caused curiosity. The description should not contain many term words as said by one participant "the fewer terminology, the better".

These groups of participants agreed that this rice product mostly was suitable for middle-aged, elderly, people with lots of stress, and people with health problem. Given the end users, one panelist thought that the first description would work better than the second idea to draw young people in because the second one would not create enough curiosity for young people, while old people wouldn't easily change their food habit. One panelist had the same thought that "The first idea makes people more curious, so for customer with knowledge and money, she/he would try to find more information about the rice" thus this would increase the chance of purchasing while the second description would be more likely to be liked by those who are less interested in nutrition and often depend on habit and experience.

To effectively convey the values of this new product to VNV consumers, nutrition information should be displayed on the package of the product. Besides, showing documentary films about the product processing on TV could be a good way to advertise this product to Vietnamese consumers.

\subsection{General discussions}

The Vietnamese groups with US residence of less than 5 years did not show much difference from the Vietnamese in their home country in terms of perception and usage of rice and attitudes towards a new healthy rice product. The USV still held a strong cultural heritage of their food habits despite changes due to lack of availability of some traditional foods and easy access to western-typed foods. This group adopted the breakfast eating patterns of the host culture because it's convenient but stayed firm with their cultural foods for dinner, which is often considered family meal for Asians. Their perception of brown rice, surprisingly, was not different from those at home, despite the increasing trend of whole grain food products in the US. Though this might be partly because of their relatively short exposure to the host culture as longer residence in the host country is believed to increase dietary acculturation [4-6,9], this could have more to do with the food beliefs that is part of Vietnamese food culture. Therefore, it would be difficult to convince this group to change their rice into brown rice. Because of this negative cultural-heritage attitude towards brown rice, acceptance of germinated brown rice was found to be difficult for this population, regardless how much nutritious it was described to be. In addition, it would be even more difficult for Vietnamese in Vietnam to accept the new rice as they have more access to traditional foods and most importantly, they do not have any urge in changing their food habits as those who migrated to a new land.

\section{CONCLUSIONS}

Dietary acculturation was found to have certain impact on Vietnamese immigrants in the US, given that they consumed more milk, dairy products, meat and breakfast cereals. However, the host culture did not have much influence on the perception of a traditional staple food of this population. Health benefit information failed to inspire this population to accept a new brown rice product despite whole grain product 
was one of the mainstreams in the US food market and healthy eating was increasingly promoted. It would take time and effort to intervene the Vietnamese immigrants' cultural foodways.

\section{ACKNOWLEDGMENTS}

This study was sponsored by the Sensory Analysis Center at Kansas State University, Manhattan, Kansas, USA. The authors greatly appreciated Ho Chi Minh-city University of Technology in Vietnam for providing facilities for the focus groups in Vietnam. The authors would like to thank Dr. Dzung H. Nguyen for his support in recruiting participants and verifying the Vietnamese version of the moderator's guides. The authors thank Sara Whetstone and Valerie Olson for their support as moderators and appreciate Panat Cherdchu and Chen Sun for their help in conducting the focus groups at Kansas State University.

\section{REFERENCES}

1. Civille, V. G.; Oftedal, N. K. Sensory evaluation techniques — Make "good for you" taste "good". Physiology \& Behavior 2012, 107, 598-605.

2. Gilbert, A. P.; Khokhar, S. Changing dietary habits of ethnic groups in Europe and implications for health. Nutrition Reviews 2008, 66(4), 203-215, doi:10.1111/j.1753-4887.2008.00025.x

3. Lee, C. M.; Lee, S. Y. Consumer insights on healthy breakfast cereal: A focus group research. J. Sens. Stud. 2007, 22, 417-432.

4. Lee, S.K.; Sobal, J.; Frongillo, E.A. Acculturation and dietary practices among Korean Americans. J Am Diet Assoc 1999, 99, 1084-1089.

5. Pan, Y.L.; Dixon, Z.; Himburg, S.; Huffman, F. Asian students change their eating patterns after living in the United States. J Am Diet Assoc 1999, 99, 54-57.

6. Raj, S.; Ganganna, P.; Bowering, J. Dietary habits of Asian Indians in relation to length of residence in the United States. J Am Diet Assoc 1999, 99, 1106-1108.

7. Satia J.A.; Patterson, R.E.; Kristal, A.R.; Hislop, T.G.; Yasui, Y.; Taylor, V.M. Development of dietary acculturation scales among Chinese Americans and Chinese Canadians. J Am Diet Assoc 2001, 101, 548553.

8. Satia, J.A.; Patterson, R. E.; Neuhouser, M. L.; Elder, J. Dietary acculturation: Applications to nutrition research and dietetics. J Am Diet Assoc 2002, 102, 1105-1118.

9. Satia, J.A.; Patterson, R.E.; Taylor, V.M.; Cheney, C.L.; Shiu-Thornton, S.; Chitnarong, K.; Kristal, A.R. Use of qualitative methods to study diet, acculturation, and health in Chinese-American women. J Am Diet Assoc 2000, 100, 934-940.

10. US Census Bureau. The Foreign Born Population in the United States: 2010, 2012. Available online: https://www.census.gov/newsroom/pdf/cspan_fb_slides.pdf (accessed on 2 July 2014).

11. Vermeer, W. M.; Steenhuis, I. H. M.; Seidell, J. C. Portion size: a qualitative study of consumers' attitudes toward point-of-purchase interventions aimed at portion size, Health Education Research 2010, 25 (1), 109-120.

12. Wan, V.C-H.; Lee, C.M.; Lee, S-Y. Understanding consumer attitudes on edible films and coatings: Focus group findings. J. Sens. Stud. 2007, 22, 353-366.

13. Wilson, C. Interview Techniques for Ux Practitioners: A User-Centered Design Method, $1^{\text {st }}$ ed; Morgan Kaufmann:Waltham, MA, USA, 2013; Chapter 5, pp 84.

14. Ziegler, R.G.; Hoover, R.N.; Pike, M.C.; Hildesheim, A.; Normura, A.M.; West, D.M.; Wu-Williams, A.H.; Kolonel, L.N.; Horn-Ross, P.L.; Rosenthal, J.F. Migration patterns and breast cancer risk in Asian American women. J. Natl. Cancer Inst. 1993, 85, 1819-1827.

\section{HOÀ NHẬP VĂN HOÁ ẦM THỰC VÀ NHU CẦU CẢI THIỆN NÔNG SẢN: MộT NGHIÊN CỨU ĐỊNH TÍNH TRÊN GẠO}

Tóm tắt. Nghiên cứu này xem xét sự khác biệt về nhận thức và niềm tin về một loại thực phẩm chính và tập trung vào việc cải thiện sản phẩm đó vì sức khỏe trong một nghiên cứu phỏng vấn nhóm tập trung sử dụng người Việt bản xứ tại Việt Nam (VNV) và người Việt nhập cư vào Hoa Kỳ (USV). Các khái niệm được điều tra là nhận thức và niềm tin về sản phẩm gạo, sử dụng và chuẩn bị gạo, và mối quan tâm chung đến các khái niệm sản phẩm gạo lứt giá trị gia tăng kết hợp ngôn ngữ liên quan đến sức khỏe. Mặc dù gạo 
trắng được cả USV và VNV chấp nhận và tiêu thụ hàng ngày, nhưng khái niệm sản phẩm gạo lứt, mặc dù có rất nhiều lợi ích cho sức khỏe, nhưng không được người tiêu dùng Việt Nam, cả ở Mỹ và Việt Nam chấp nhận. Cả hai nhóm người tiêu dùng đều có mối liên hệ tiêu cực về mặt văn hóa của gạo lứt với nghèo đói, lão hóa và bệnh tật ở Việt Nam và những nhận thức đó không thay đổi khi nhập cư. Cả người tiêu dùng USV và VNV đều không coi lợi ích sức khỏe là yếu tố chính cho tiêu thụ gạo, một loại lương thực chính trong tất cả các chế độ ạn kiêng của họ. Tiếp xúc với văn hóa Hoa Kỳ dường như ít ảnh hưởng đến thói quen ăn cơm của người Mỹ gốc Việt. Do đó, đối với một sản phẩm thực phẩm chủ yếu, có vẻ như sẽ mất thời gian và nỗ lực đáng kể để tác động đến người nhập cư Việt Nam.

Từ khóa: văn hóa, gạo, gạo lứt, focus groups, khẩu vị

Ngày nhận bài: 13/04/2020

Ngày chấp nhận đăng: 18/06/2020 